\title{
Perancangan Proses Remanufaktur pada Komponen Otomotif
}

\author{
Yopi Yusuf Tanoto ${ }^{1 *}$, Didik Wahjudi' ${ }^{2}$ Ricky Kurniawan $\mathrm{Njo}^{3}$ \\ 1,2,3 Program Studi Teknik Mesin, Fakultas Teknologi Industri, Universitas Kristen Petra \\ Jl. Siwalankerto 121-131, Surabaya 60236, Indonesia \\ *Penulis korespondensi; E-mail: yopi.tanoto@petra.ac.id
}

\begin{abstract}
ABSTRAK
Kendaraan telah menjadi salah satu kebutuhan penting bagi manusia dalam berbagai aktifitas sehari-hari. Jumlah sepeda motor menunjukkan peningkatan dalam setiap tahunnya. Hal ini menyebabkan limbah berupa komponen yang rusak dari sebuah kendaraan juga terus meningkat. Saat ini, beberapa bentuk dari limbah tersebut dapat direcycle agar materialnya dapat dimanfaatkan kembali. Beberapa komponen yang telah rusak sebenarnya masih dapat digunakan lagi dengan beberapa proses seperti repair, refurbish atau remanufaktur. Proses remanufaktur adalah salah satu recovery option paling tinggi dalam mengolah limbah. Dalam melakukan perancangan proses remanufaktur untuk komponen-komponen otomotif, perlu adanya pemilihan komponen yang akan dijadikan objek. Setelah pemilihan objek, maka harus dibuat serangkaian proses yang harus ada di dalam proses remanufaktur komponen otomotif seperti disassembly, cleaning, inspection, recondition, dan reassembly. Tahap akhirnya adalah merancang skema proses remanufaktur untuk komponen otomotif. Ciri khas dalam proses remanufaktur komponen otomotif adalah adanya special treatment seperti normalizing, hardening untuk beberapa komponen otomotif yang berguna untuk mengembalikan atau bahkan meningkatkan performa atau mechanical properties dari komponen yang diremanufaktur.
\end{abstract}

Kata kunci: Komponen; otomotif; remanufaktur; special treatment.

\begin{abstract}
Vehicle has become one of the important needs for humans in daily activities. The number of motorbikes shows an increase every year. This causes a continuing growth in waste which is in the form of damaged component from a vehicle. Currently, some types of the waste can be recycled so that the material can be reused. Some components that have been damaged, in fact, can still be used again with several processes such as repair, refurbish or remanufacturing. The remanufacturing process is one of the highest recovery options in treating the waste. In designing the remanufacturing process for automotive components, the selection of components to be regarded as object is necessary. After the object selection, a series of processes which are pertinent and required in the remanufacturing process of automotive components such as disassembly, cleaning, inspection, recondition, and reassembly, must be made. The final stage is to design the scheme of a remanufacturing process for automotive component. Characteristics in the remanufacturing process of automotive component manifest in required special treatments such as normalizing, hardening for automotive components that is convenient to restore or even improve the performance or mechanical properties of remanufactured components.
\end{abstract}

Keywords: Components; automotive; remanufacturing; special treatment.

\section{PENDAHULUAN}

Dalam industri manufaktur, terdapat proses yang diketahui sebagai proses remanufaktur. Proses remanufaktur adalah proses dimana suatu perusahaan membuat barang yang sudah habis masa pakainya menjadi seperti barang baru lewat berbagai proses; salah satunya adalah dengan rekondisi dan dengan memberikan garansi seperti barang barunya [1].
Menurut Steinhilper [2], proses remanufaktur merupakan proses untuk memperbaiki suatu barang yang tidak digunakan menjadi barang yang seperti barang baru sehingga hal ini menjadi sebuah solusi untuk mengurangi jumlah barang bekas dan dapat mengurangi biaya pemiliknya serta dapat meningkatkan profit. Proses remanufaktur juga berkontribusi untuk menjaga lingkungan karena remanufaktur dapat mengurangi sampah dari komponen yang seharusnya menjadi sampah karena masa pakainya 
telah habis namun komponen tersebut dapat dipakai kembali. Sangat sedikit perusahaan remanufaktur yang ada di Indonesia dikarenakan ketiadaan beberapa industri yang memiliki kapasitas untuk memproses kembali barang tidak terpakai menjadi produk remanufaktur. Selain itu, hal lain yang menjadi persoalan adalah belum ditemukannya langkahlangkah pedoman melakukan remanufaktur untuk produk otomotif khususnya sepeda motor. Yang menjadi tantangan adalah bagaimana agar hasil produk remanufaktur harus mempunyai kualitas yang sama dengan kualitas produk baru aslinya [3].

Indonesia adalah negara dengan jumlah kendaraan bermotor khususnya sepeda motor yang cukup banyak. Dilansir melalui website resmi Badan Pusat Statistik Indonesia bahwa pada tahun 2016 tercatat jumlah kendaraan bermotor sebanyak 129,281,079 unit [4]. Penyumbang unit kendaraan terbanyak adalah sepeda motor sebesar 105,150,082 unit dan mobil penumpang sebesar 14,580,666 unit. Jumlah kendaraan bermotor tersebut sangatlah besar. Dengan adanya peningkatan jumlah penggunaan kendaraan bermotor, maka banyak juga kendaraan yang mengalami kerusakan dan pergantian komponen. Kerusakan ini disebabkan karena adanya penggunaan yang tidak wajar, produk otomotif yang sudah lama, perawatan dan pembersihan yang jarang dilakukan. Selain karena kerusakan, kendaraan yang tidak terpakai juga akan menjadi sampah otomotif. Berdasarkan data yang diperoleh, pertumbuhan kendaraan baru di Jakarta setiap hari mencapai 1500 unit dimana sepeda motor adalah penyumbang terbesar yakni 1200 unit [5]. Banyaknya kendaraan baru setiap harinya di Indonesia akan mengakibatkan bertambahnya kendaraan bekas. Kerusakan dan kendaraan bekas tersebut dapat menjadi sampah otomotif dan salah satu cara untuk mengatasinya adalah dengan melakukan proses remanufaktur.

\section{METODE PENELITIAN}

Dalam penelitian ini dilakukan studi pustaka tentang proses remanufaktur pada komponen otomotif. Komponen otomotif yang ditemui biasanya berupa alat berat. Selanjutnya peneliti memilih komponen yang akan dilakukan remanufaktur dan menganalisa proses apa yang harus ada. Komponen yang dipilih adalah komponen yang memiliki kriteria seperti mudah rusak. Harga komponen dan kriteria lainnya dijelaskan pada bagian pembahasan.

Setiap komponen pasti memiliki cara atau langkah-langkah proses remanufaktur yang berbeda. Dalam proses remanufaktur terdapat langkah yang disebut repair atau rekondisi yang merupakan hal penting untuk membuat komponen otomotif dapat digunakan kembali. Dalam penelitian, agar dapat diketahui bagaimana proses repair dilakukan beberapa langkah seperti studi lapangan, visitasi tempat-tempat perbaikan komponen otomotif diperlukan. Dari hasil analisa tersebut, kemudian dirancang dan dibuat rangkaian proses remanufaktur komponen otomotif. Selanjutnya pada tahap akhir, peneliti membuat kesimpulan tentang hasil dari rancangan proses remanufaktur.

\section{HASIL DAN PEMBAHASAN}

Terdapat banyak komponen yang ada dalam sebuah produk otomotif. Untuk memilih komponen yang akan dilakukan remanufaktur, beberapa kriteria dimunculkan. Dalam pemilihan obyek komponen remanufaktur, digunakan kriteria pemilihan komponen remanufaktur menurut Bobek [6], yaitu:

- The product is durable;

- The product has only failed in its functionality;

- The product is standardized and consists of interchangeable parts;

- The added value at end of life is high;

- The cost to obtain the core is low if compared with the remaining intrinsic value;

- The product's technology is relatively stable over a period of time that exceeds the single lifecycle;

- The consumer should be informed about the availability of remanufactured products, so to create an adequate demand on the market;

- A technology exists to remove parts from products without damaging them and to restore the product.

Beberapa kriteria di atas dapat disederhanakan menjadi beberapa kategori. Setiap kategori akan diberikan bobot berdasarkan tingkat kepentingannya. Semakin besar bobotnya, berarti semakin penting kategori tersebut dibandingkan dengan kategori yang lain. Adapun kategori tersebut adalah:

- Volume (30\%);

- High value (30\%);

- Fast moving (25\%);

- Teknologi dan desain tidak berubah (15\%).

Dari 10 komponen yang digunakan, terpilih 5 komponen untuk dilakukan remanufaktur sesuai dengan kriteria di atas. Komponen terpilih adalah komponen yang memiliki score paling tinggi (ditandai dengan warna merah), sebagaimana ditunjukkan Tabel 1. Nilai ditentukan 1 sampai dengan 10. Semakin besar nilainya, maka komponen tersebut memiliki tingkat kesesuaian dengan kriteria yang dibuat. Score diperoleh dari penjumlahan nilai dikalikan dengan bobot dari setiap kriteria.

Berdasarkan Tabel 1, dipilihlah blok silinder, jok, kampas rem tromol, shock breaker, dan pelek atau velg yang akan diremanufaktur. Berikut adalah rancangan remanufaktur pada pelek atau velg, shock breaker, blok silinder, sepatu rem tromol, dan jok sepeda motor. 
Tabel 1. Peringkat komponen otomotif

\begin{tabular}{|c|c|c|c|c|c|c|c|c|c|c|}
\hline No & $\begin{array}{c}\text { Nama } \\
\text { komponen }\end{array}$ & \multicolumn{2}{|c|}{ Volume } & \multicolumn{2}{|c|}{ High value } & \multicolumn{2}{|c|}{ Fast moving } & \multicolumn{2}{|c|}{$\begin{array}{c}\text { Teknologi dan } \\
\text { desain tidak } \\
\text { berubah }\end{array}$} & Score \\
\cline { 3 - 11 } & & nilai & $\begin{array}{c}\text { Bobot } \\
(30 \%)\end{array}$ & nilai & $\begin{array}{c}\text { Bobot } \\
(30 \%)\end{array}$ & nilai & $\begin{array}{c}\text { Bobot } \\
(25 \%)\end{array}$ & $\begin{array}{c}\text { Nilai } \\
\text { Bobot } \\
(15 \%)\end{array}$ & \\
\hline 1 & $\begin{array}{c}\text { Blok } \\
\text { silinder }\end{array}$ & 5 & 1,50 & 8 & 2,40 & 7 & 1,75 & 5 & 0,75 & 6,40 \\
\hline 2 & $\begin{array}{c}\text { Cover } \\
\text { kepala }\end{array}$ & 1 & 0,30 & 9 & 2,70 & 1 & 0,25 & 4 & 0,60 & 3,85 \\
\hline 3 & Jok & 2 & 0,60 & 6 & 1,80 & 9 & 2,25 & 6 & 0,90 & 5,55 \\
\hline 4 & $\begin{array}{c}\text { Kampas } \\
\text { kopling }\end{array}$ & 6 & 1,80 & 5 & 1,50 & 8 & 2,00 & 1 & 0,15 & 5,45 \\
\hline 5 & $\begin{array}{c}\text { Kampas } \\
\text { rem tromol }\end{array}$ & 9 & 2,70 & 3 & 0,90 & 10 & 2,50 & 10 & 1,50 & 7,60 \\
\hline 6 & Klakson & 10 & 3,00 & 1 & 0,30 & 4 & 1,00 & 8 & 1,20 & 5,50 \\
\hline 7 & $\begin{array}{c}\text { Rumah } \\
\text { roller }\end{array}$ & 4 & 1,20 & 4 & 1,20 & 6 & 1,50 & 3 & 0,45 & 4,35 \\
\hline 8 & $\begin{array}{c}\text { Shock } \\
\text { breaker }\end{array}$ & 7 & 2,10 & 7 & 2,10 & 5 & 1,25 & 9 & 1,35 & 6,80 \\
\hline 9 & Spion & 3 & 0,90 & 2 & 0,60 & 2 & 0,50 & 7 & 1,05 & 3,05 \\
\hline 10 & Pelek & 8 & 2,40 & 10 & 3 & 3 & 0,75 & 2 & 0,30 & 6,45 \\
\hline
\end{tabular}

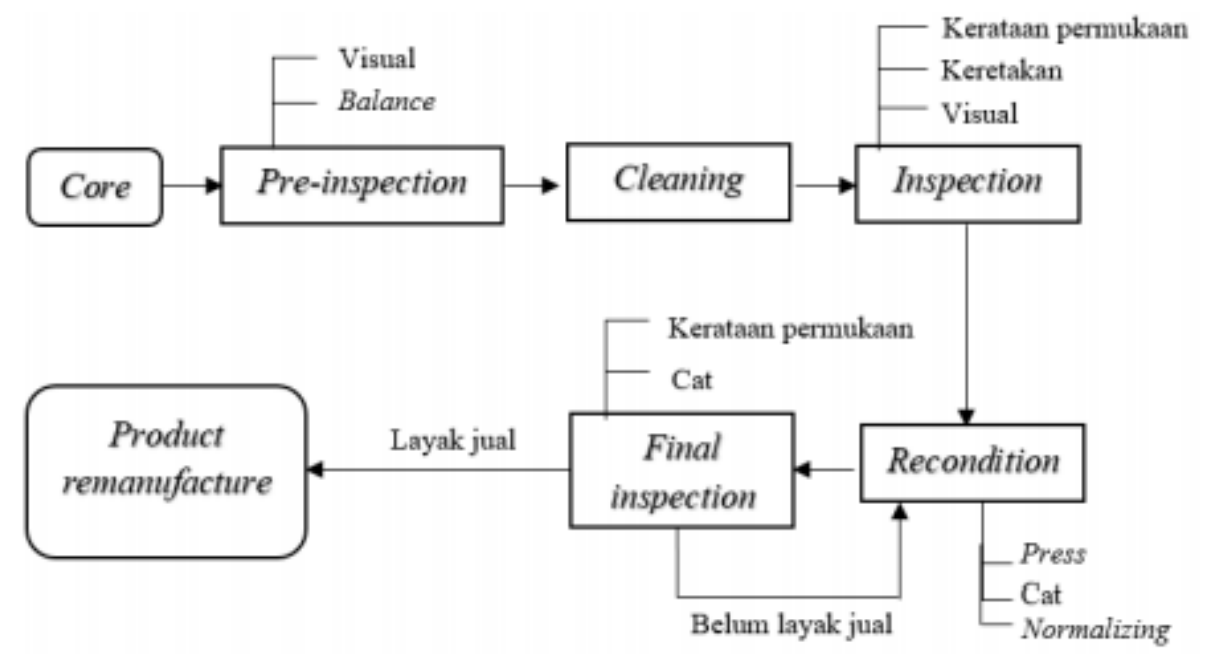

Gambar 1. Rancangan proses remanufaktur pelek

\section{Pelek atau Velg}

Pelek yang didapat dari penyuplai harus melewati tahap pre-inspection untuk menentukan apakah pelek tersebut layak untuk dilakukan remanufaktur atau tidak. Pre-inspection dilakukan secara visual. Bila kerusakan pelek tersebut cukup parah, maka pre-inspection tidak dilanjutkan ke proses berikutnya. Selanjutnya pelek menjalani proses cleaning untuk dibersihkan dan untuk dapat melewati proses inspection.

Pada proses inspection, pengecekan dilakukan melalui pengukuran dan secara visual untuk menentukan apakah pelek dapat digunakan kembali atau perlu diperbaiki. Kriteria dari proses inspection adalah bila tidak dijumpai penyok atau retak pada pelek, maka pelek tidak perlu diperbaiki. Ultrasonic flaw detector juga digunakan dalam proses inspection. Bila pelek perlu diperbaiki, pelek harus menjalani tahap recondition.

Perbaikan pelek meliputi proses press, cat ulang dan normalizing, sesuai dengan kondisi pelek. Setelah pelek diperbaiki, pelek diuji kembali melalui final inspection dengan menggunakan kriteria yang sama dari inspeksi awal. Final inspection bertujuan untuk menentukan kondisi pelek apakah layak untuk dijual kembali atau belum layak dijual. Pelek yang layak dijual menjadi produk remanufaktur, 
sedangkan pelek yang belum layak jual perlu diperbaiki lagi. Gambar rancangan proses remanufaktur pelek dapat dilihat pada Gambar 1.

\section{Shock Breaker}

Shock breaker yang didapat dari penyuplai harus melewati tahap pre-inspection yang dilakukan secara visual untuk menentukan apakah shock breaker tersebut layak untuk dilakukan remanufaktur atau tidak. Shock breaker yang layak dilakukan remanufaktur menjalani proses disassembly untuk dibongkar setiap komponennya. Bagian damper perlu dibongkar untuk mengganti part keluar, yaitu: bosh, seal, o-ring, oli, as, bantalan, dan tabung bagian dalam diganti dengan yang baru.

Selanjutnya, shock breaker menjalani proses cleaning untuk dibersihkan serta menjalani proses inspection. Pada proses inspection, pengecekan dilakukan melalui pemberian gaya pada pegas dan visual untuk menentukan apakah komponen shock breaker dapat digunakan kembali, diperbaiki, atau perlu diganti baru. Bila shock breaker perlu diperbaiki, shock breaker menjalani tahap recondition. Perbaikan shock breaker meliputi cat ulang dan normalizing karena barang yang didapatkan dari penyuplai memiliki cat yang tidak sama dengan yang baru/kusam serta untuk menghilangkan tegangan sisa.

Setelah shock breaker diperbaiki, shock breaker menjalani proses reassembly untuk perakitan ulang. Setelah melewati semua proses, shock breaker diuji kembali melalui final inspection untuk menentukan kondisi shock breaker apakah layak untuk dijual kembali atau belum layak jual. Shock breaker yang layak dijual menjadi produk remanufaktur, sedangkan shock breaker yang belum layak jual perlu diperbaiki lagi. Gambar rancangan proses remanufaktur shock breaker dapat dilihat pada Gambar 2.

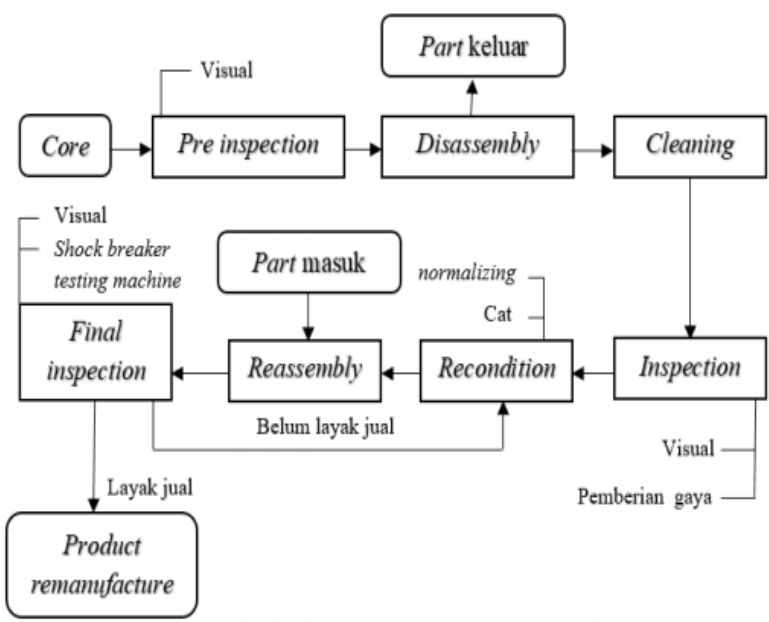

Gambar 2. Gambar rancangan proses remanufaktur shock breaker.

\section{Blok silinder}

Blok silinder yang didapat dari penyuplai harus melewati tahap pre-inspection untuk menentukan apakah blok silinder tersebut layak untuk dilakukan remanufaktur atau tidak. Blok silinder yang layak dilakukan remanufaktur harus menjalani proses disassembly untuk dibongkar setiap komponennya. Setelah itu, blok silinder menjalani proses cleaning untuk dibersihkan dan kemudian menjalani proses inspection.

Pada proses inspection, pengecekan dilakukan dengan menggunakan dial bore gauge dan ultrasonic flaw detector digunakan untuk mengecek apakah dinding blok silinder dalam keadaan yang rata atau tidak serta terjadi keretakan atau tidak. Jika dinding permukaan blok silinder tidak rata atau terjadi keretakan, maka blok silinder harus diganti baru. Setelah blok silinder diinspeksi, blok silinder menjalani proses reassembly untuk perakitan ulang.

Blok silinder diinspeksi kembali dengan menggunakan dial bore gauge untuk mengecek apakah blok silinder terpasang dengan baik atau tidak. Blok silinder yang sudah melewati semua proses menjadi produk remanufaktur yang siap untuk dijual kembali. Gambar rancangan proses remanufaktur blok silinder dapat dilihat pada Gambar 3.

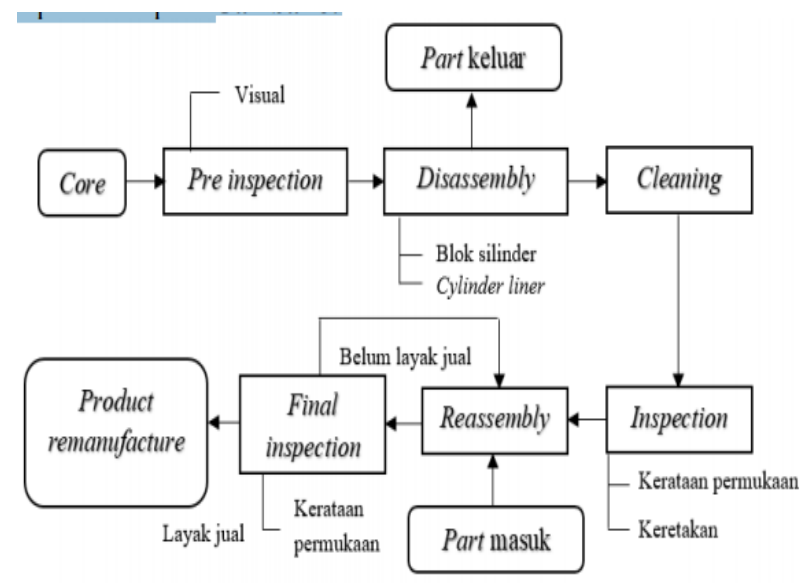

Gambar 3. Rancangan proses remanufaktur blok silinder.

\section{Sepatu Rem Tromol}

Sepatu rem tromol yang didapat dari penyuplai harus melewati tahap pre-inspection untuk menentukan sepatu rem tromol tersebut layak untuk dilakukan remanufaktur atau tidak. Sepatu rem tromol kemudian menjalani proses cleaning untuk dibersihkan. Selanjutnya, sepatu rem tromol diinspeksi dengan menggunakan ultrasonic flaw detector untuk mengecek apakah terjadi keretakan atau tidak. Apabila keretakan terjadi pada sepatu rem tromol, maka sepatu rem tromol tersebut tidak dapat digunakan. 
Setiap sepatu rem tromol kemudian menjalani proses recondition. Dalam proses recondition ini, perbaikan sepatu rem tromol meliputi proses press dan cat ulang dimana kedua proses tersebut bergantung pada kondisi sepatu rem tromol. Setelah sepatu rem tromol diperbaiki, sepatu rem tromol menjalani proses reassembly untuk perakitan ulang.

Setelah selesai semua proses, sepatu rem tromol diinspeksi dengan menggunakan high flexural strength friction. Sepatu rem tromol yang sudah melewati semua proses menjadi produk remanufaktur yang siap untuk dijual kembali. Gambar rancangan proses remanufaktur sepatu rem tromol dapat dilihat pada Gambar 4.

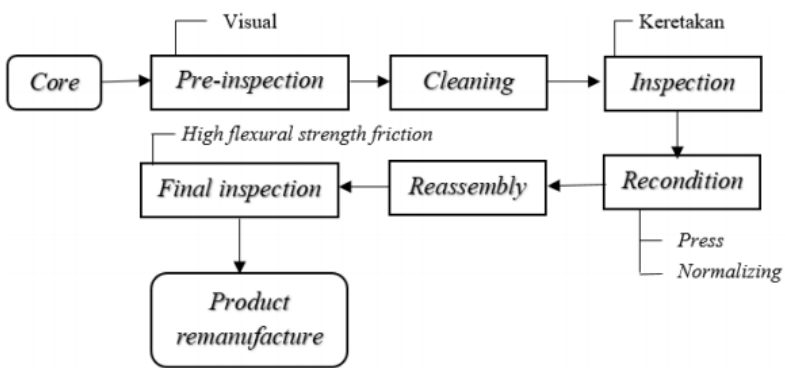

Gambar 4. Rancangan proses remanufaktur sepatu rem tromol.

\section{Jok}

Jok yang didapat dari penyuplai harus melewati tahap pre-inspection untuk menentukan apakah jok tersebut layak untuk dilakukan remanufaktur atau tidak. Jok yang layak dilakukan remanufaktur harus menjalani proses disassembly untuk dibongkar setiap komponennya. Selanjutnya jok menjalani proses cleaning untuk dibersihkan serta menjalani proses inspection.

Pada proses inspection, pengecekan dilakukan secara visual dan ultrasonic flaw detector digunakan untuk mengecek apakah base jok mengalami keretakan atau tidak. Jika base jok mengalami keretakan, maka base jok tersebut harus diganti baru. Setelah itu base jok harus menjalani proses reassembly untuk perakitan ulang.

Jok sepeda motor yang sudah melewati semua proses menjadi produk remanufaktur yang siap untuk dijual kembali. Gambar rancangan proses remanufaktur jok sepeda motor dapat dilihat pada Gambar 5.

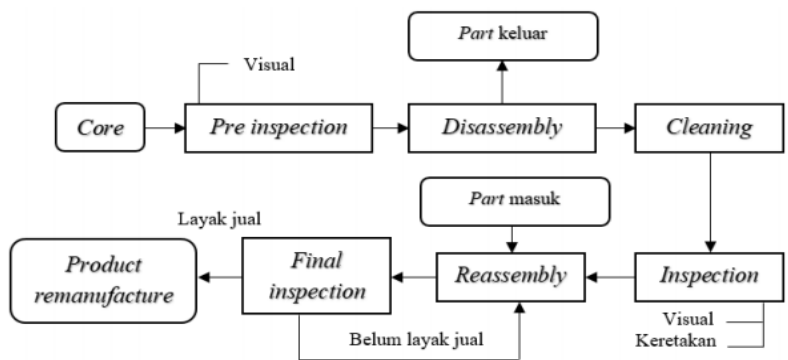

Gambar 5. Rancangan proses remanufaktur jok sepeda motor
Terlepas dari itu semua, dalam langkah-langkah proses remanufaktur terdapat beberapa kesulitan yang disebabkan oleh karena desain awal produk tersebut. Kesulitan-kesulitan tersebut dapat diminimalisir jika desain awal dari produk tersebut ditujukan untuk mendukung proses remanufaktur pada akhirnya.

Tabel 2. Rekomendasi Desain dan Proses untuk Mendukung Proses Remanufaktur Komponen Otomotif.

\begin{tabular}{|c|c|c|}
\hline $\begin{array}{l}\text { Komponen } \\
\text { Otomotif }\end{array}$ & Hambatan & Rekomendasi \\
\hline $\begin{array}{l}\text { Pelek atau } \\
\text { velg }\end{array}$ & $\begin{array}{l}\text { Bibir pelek sering } \\
\text { mengalami } \\
\text { bengkok karena } \\
\text { bibir pelek } \\
\text { memiliki ketebalan } \\
\text { yang tipis dan lebih } \\
\text { bersifat ulet. }\end{array}$ & $\begin{array}{l}\text { Melakukan } \\
\text { proses hardening } \\
\text { pada bibir pelek } \\
\text { untuk membuat } \\
\text { kekerasan dari } \\
\text { bibir pelek } \\
\text { meningkat } \\
\text { sehingga pelek } \\
\text { mempunyai sifat } \\
\text { getas. }\end{array}$ \\
\hline $\begin{array}{l}\text { Shock } \\
\text { breaker }\end{array}$ & $\begin{array}{l}\text { Untuk menutup } \\
\text { bagian damper, } \\
\text { sambungan las } \\
\text { digunakan } \\
\text { sehingga hal ini } \\
\text { mengakibatkan } \\
\text { saat melakukan } \\
\text { proses } \\
\text { pembongkaran } \\
\text { perlu dipotong dan } \\
\text { menyebabkan } \\
\text { tinggi damper } \\
\text { berkurang. }\end{array}$ & $\begin{array}{l}\text { Mengubah } \\
\text { sambungan las } \\
\text { menjadi } \\
\text { sambungan ulir } \\
\text { karena } \\
\text { sambungan ulir } \\
\text { dapat } \\
\text { mempermudah } \\
\text { proses pelepasan } \\
\text { dan } \\
\text { pemasangan. }\end{array}$ \\
\hline $\begin{array}{l}\text { Sepatu rem } \\
\text { tromol }\end{array}$ & $\begin{array}{l}\text { Pemasangan } \\
\text { sepatu rem tromol } \\
\text { dan kampas } \\
\text { menggunakan lem } \\
\text { sebagai } \\
\text { perekatnya. Untuk } \\
\text { proses } \\
\text { pelepasannya, } \\
\text { kampas rem } \\
\text { dihancurkan } \\
\text { dengan } \\
\text { menggunakan alat } \\
\text { pahat yang } \\
\text { memerlukan } \\
\text { waktu cukup lama } \\
\text { dan menyisakan } \\
\text { sisa lem. }\end{array}$ & $\begin{array}{l}\text { Mengganti } \\
\text { sambungan lem } \\
\text { dengan } \\
\text { sambungan } \\
\text { keling. } \\
\text { Sambungan } \\
\text { keling akan } \\
\text { mempermudah } \\
\text { waktu proses } \\
\text { pembongkaran } \\
\text { dan perakitan. } \\
\text { Kampas rem } \\
\text { tromol dengan } \\
\text { sambungan } \\
\text { keling juga } \\
\text { sudah } \\
\text { diaplikasikan } \\
\text { pada truk. }\end{array}$ \\
\hline $\begin{array}{l}\text { Jok sepeda } \\
\text { motor }\end{array}$ & $\begin{array}{l}\text { Staples digunakan } \\
\text { dalam } \\
\text { pemasangan base } \\
\text { dan kulit. Hal ini } \\
\text { dapat } \\
\text { menyebabkan } \\
\text { bagian base rusak. }\end{array}$ & $\begin{array}{l}\text { Setiap pinggiran } \\
\text { jok dilubangi dan } \\
\text { keling digunakan } \\
\text { untuk } \\
\text { menyatukan } \\
\text { antara base } \\
\text { dengan kulit } \\
\text { (yang sudah } \\
\text { dilubangi juga). }\end{array}$ \\
\hline
\end{tabular}




\section{KESIMPULAN}

Dalam penelitian ini terlihat bahwa langkahlangkah pada proses remanufaktur untuk komponen otomotif tidak sama antara komponen yang satu dengan komponen yang lain. Sebagai contoh, pada pelek proses disassembly tidak ada yang mana proses tersebut dilakukan oleh supplier sedangkan pada shock breaker langkah disassembly diperlukan.

Selain adanya perbedaan tersebut tetap ada suatu kesamaan yang menjadi karakteristik pada proses remanufaktur komponen otomotif khususnya sepeda motor dibandingkan dengan proses remanufaktur pada produk lainnya. Karakteristik tersebut yaitu pada semua komponen atau part yang selama masa pakainya atau pengujiannya menerima gaya maka perlu dilakukan perlakuan khusus pada komponen tersebut. Salah satu contoh perlakuan khusus tersebut adalah normalizing yang bertujuan untuk menghilangkan tegangan sisa pada bagian dari komponen yang muncul selama masa pakai.

Hal krusial lain yang ditemukan dari penelitian ini adalah terdapat kesulitan saat melakukan langkah-langkah proses remanufaktur. Hal tersebut ditengarai karena memang komponen tersebut tidak dirancang atau didesain sebagai komponen untuk dilakukan remanufaktur.

\section{DAFTAR PUSTAKA}

[1]. Debo, L. G., Wassenhove, L. V., Toktay, B., 2006, "Life Cycle Dynamics for Portfolios with Remanufactured Products", Product and Operation Management, 15, pp. 1-25.

[2]. Steinhilper, R., 1998, Remanufacturing the Ultimate Form of Recycling, Fraunhofer IRB Verlag, Stuttgart, Germany.

[3]. Thierry, M., Salomon, M., Nunen, J. V., Wassenhove, L. V., 1995, "Strategic Issue Product Recovery Management", California Management Review, 37, 2, pp. 114-135.

[4]. Badan Pusat Statistik Indonesia, Perkembangan Jumlah Kendaraan Bermotor Menurut Jenis, 1949-2018. (Diunduh dari: https://www.bps.go. id/linkTableDinamis/view/id/1133).

[5]. Maulana, Setiap Hari Ada 1.500 Kendaraan Baru di Jakarta. (Diunduh dari: https://otomotif. kompas.com/read/2018/09/13/124200115/setiaphari-ada-1.500-kendaraanbaru-di-jakarta).

[6]. Bobek, V., 2012, International Trade from Economic and Policy Perspective, Intech Open, London, United Kingdom. 